\title{
A retórica e as paixões no Prefácio de Hans Kelsen: notas sobre o sujeito, o discurso e a Teoria Pura do Direito
}

\author{
Adriana do Carmo Figueiredo \\ Mestre em Estudos Literários e doutoranda em Estudos Linguísticos pela Universidade \\ Federal de Minas Gerais (UFMG), Brasil. \\ acfigueiredo.prof@gmail.com
}

Resumo: Este artigo tem como proposta discutir a implicação das emoções no Prefácio que Hans Kelsen escreveu, em 1934, quando publicou sua primeira edição da Teoria Pura do Direito. O objetivo é analisar enunciados e enunciações que são reveladores não apenas do discurso kelseniano sobre a sua noção do Direito positivo, mas também as marcas retórico-enunciativas da inscrição do sujeito produtor e enunciador desse discurso. A análise metodológica do corpus se deu por meio da Retórica das Paixões de Aristóteles, em diálogo com teorias desenvolvidas por Meyer (2000, 2007), além da Teoria Semiolinguística de Charaudeau (2001) e das teorizações sobre narrativas de vida propostas por Machado (2014). Como resultado preliminar, comprovamos que há elementos do Pathos, na construção retórico-enunciativa desse Prefácio, que revelam as relações entre sujeito, teoria e discurso. Concluímos que a expressão das emoções no discurso kelseniano sugere chaves de leitura para novas abordagens sobre os estudos da argumentação.

Palavras-chave: Retórica. Argumentação. Prefácio. Hans Kelsen.

\begin{abstract}
This article aims to discuss the implication of emotions in the Preface that Hans Kelsen wrote in 1934 when he published his first edition of Pure Theory of Law. The objective is to analyze statements and enunciations that reveal not only the Kelsenian discourse about his notion of positive law, but also the rhetorical-enunciative marks that lead to the recognition of the inscription of the subject. The methodological analysis took place through the Aristotle's Rhetoric of Passions, the theories by Meyer (2000, 2007), the Semiolinguistic Theory of Charaudeau (2001) and the theorizations about narratives of life proposed by Machado (2014). As a preliminary result, we found that there are elements of the Pathos, in the rhetoric-enunciative construction of this Preface, that reveal the relations between subject, theory and discourse. We concluded that the emotions in the Kelsenian discourse suggest keys of reading that are relevant to approaches to argumentation studies.
\end{abstract}

Keywords: Rhetoric. Argumentation. Preface. Hans Kelsen. 
Introdução

Este artigo é fruto de uma pesquisa que desenvolvemos no Seminário sobre Retórica, Argumentação e Emoções, disciplina ministrada pela professora Dra. Helcira Maria Rodrigues de Lima, no programa de Estudos Linguísticos do PosLin/FALE-UFMG, no $2^{\circ}$ semestre de 2017. Referida pesquisa foi apresentada, na modalidade comunicação, nas IV Jornadas da Associação Latino-Americana de Retórica / V Congresso Brasileiro de Retórica, eventos realizados nas Faculdades de Letras (FALE), Filosofia e Ciências Humanas (FAFICH) da Universidade Federal de Minas Gerais (UFMG), nos dias 20, 21, 23 e 24 de agosto de 2018, e na cidade de Ouro Preto, no dia 22 de agosto de 2018.

Segundo a pesquisadora Helcira Lima (2016), os estudos referentes à argumentação passaram por uma reinvenção, no século $X X$, em razão dos processos de formalização da Lógica e da consequente deslegitimação da Retórica, no século XIX'. Essa nova perspectiva dos estudos sobre a argumentação ganha respaldo, nos anos de 1950, e traz as contribuições de Perelman e Olbrechts-Tyteca, Toulmin e outros pensadores.

Lima (2016) comenta que a Retórica passou a ser considerada inadequada ao conhecimento de origem positivista e, assim, "foi progressivamente excluída dos cursos fundamental, médio e universitário, na França e em outras partes do mundo" (LIMA, 2016, p. 241).

Esse fato desencadeador da crença de que a Retórica era "imprópria ao saber positivista" (LIMA, 2016, p. 241) nos parece particularmente interessante, se considerarmos que o positivismo jurídico, por exemplo, foi construído no seio dos mecanismos argumentativos da lógica formal e das estratégias de persuasão do auditório. Ao que parece ser, o positivismo, então, se valeu de mecanismos retóricos para construir a noção da norma fundamental ${ }^{2}$, perspectiva defendida por Hans Kelsen, em 1934, e, posteriormente, desconsiderou a relevância da Retórica para a continuidade do saber que emergia da própria configuração positivista.

\footnotetext{
${ }^{1}$ Lima (2016) destaca que esta é uma perspectiva defendida por Plantin (1996).

${ }^{2}$ Segundo Kelsen, "a norma que representa o fundamento de validade de uma outra norma é, em face desta, uma norma superior" (KELSEN, 2003, p. 217). Desta forma, todo questionamento a respeito da validade de uma determinada norma "não pode, tal como a investigação da causa de um determinado efeito, perder-se no interminável. Tem de terminar numa norma que se pressupõe como a última e a mais elevada" (KELSEN, 2003, p. 217).
} 
Os discursos argumentativos de Kelsen que criaram essa noção de norma fundamental se perpetuaram no meio jurídico e, por isso, muitos constitucionalistas se apropriaram da teoria da pirâmide kelseniana ${ }^{3}$ para formularem as noções nas quais a Constituição adquire esse status de norma fundamental. Isso leva a um desencadeamento de institutos jurídicos que conduzem às noções de rigidez constitucional e de sistema protetivo, que visam a resguardar a integridade da Constituição.

Acreditamos que, no centro da argumentação tanto de Kelsen quanto de Aristóteles, encontra-se a razão que leva ao conhecimento. Consequentemente, nota-se a discussão sobre a verdade que se esconde ou se revela no discurso jurídico e nos arcabouços da Retórica, ambos, por sua vez, se estruturam também pelos arranjos das paixões, como vertente do componente humano.

Nessa caminhada entre razão e emoção, a figura do sujeito produtor do discurso positivista, propagado pelo Direito, sugere uma especial atenção e alguns questionamentos: qual é a imagem que o jurista e magistrado de Viena, Hans Kelsen, constrói de si ao defender sua Teoria Pura do Direito? Como a palavra é articulada por Kelsen em defesa da sua construção teórica? Existem mecanismos da retórica argumentativa empregados pelo jurista na elaboração do seu positivismo jurídico?

As respostas aos questionamentos supracitados nos parecem possíveis quando analisamos o Prefácio à $1^{\mathrm{a}}$ edição da Teoria Pura do Direito, escrito por Kelsen, em 1934. Esse texto deixa entrever o contexto histórico que desencadeou a escrita do seu tratado sobre o direito, as condições de produção de sua doutrina jurídica, bem como os discursos que se manifestaram, na época, em aprovação ou rejeição da sua obra. É especialmente nesse arcabouço discursivo que pretendemos analisar as relações entre a Retórica e as paixões que, conforme Aristóteles, estão envoltas nos discursos argumentativos por meio das articulações persuasivas.

\footnotetext{
${ }^{3}$ Esclarecemos que a teoria do ordenamento jurídico estruturado em pisos, em outras palavras, a teoria do sistema jurídico entendido como uma pirâmide, está exposta nas principais obras de Kelsen (2000, 2003), especialmente na Teoria Geral do Direito e do Estado e na Teoria Pura do Direito. De acordo com Gusmão (2018), no Estado moderno, "a Constituição e as emendas constitucionais presidem a disposição orgânica das demais fontes formais do direito. Daí Kelsen organizá-las em pirâmide jurídica, em cujo vértice está a Constituição. Depois da lei constitucional vem a lei complementar, que não chega a ser norma constitucional, mas que a completa, e, abaixo dela, a lei ordinária (lei do divórcio, Código Penal etc.), que está subordinada à constitucional e à lei complementar (quando houver), não podendo, nas Constituições rígidas, violá-las, sob pena de ser inconstitucional" (GUSMÃO, 2018, p. 106-107).
} 


\section{$\mathrm{EI} \square \mathrm{dA}$}

Importante destacar que se trata de uma análise que parte do ponto de vista daquele que assina o Prefácio.

Feito esse panorama, destacamos que o corpus entrecortado para a análise é composto por esse Prefácio, de onde foram extraídos alguns excertos para este estudo. Nessa materialidade discursiva, buscaremos analisar as pistas das narrativas de vida (MACHADO, 2014) do jurista austríaco que revelam as condições de produção da sua obra. O objetivo é analisar enunciados e enunciações que revelam não apenas o discurso kelseniano sobre a sua noção do Direito positivo desvinculado da ideologia política, mas também as marcas retórico-enunciativas que levam ao reconhecimento da inscrição do sujeito produtor e enunciador desse discurso. Desse modo, pretendemos compreender os efeitos patêmicos ${ }^{4}$ que se encontram nesse Prefácio de Hans Kelsen, ao defender e justificar a sua obra Teoria Pura do Direito.

Importante comentar que esta análise se vale da noção dos sujeitos enunciadores, convocados pelo sujeito comunicante Kelsen, e, por isso, será utilizada a abordagem de Patrick Charaudeau (2001) sobre os sujeitos da linguagem e seus papéis sociais, conforme o "quadro teórico" proposto por Charaudeau (1983), em sua teoria Semiolinguística.

A hipótese desta pesquisa se sustenta na perspectiva de que a construção kelseniana sobre a teoria do Direito se espelha nos discursos retóricos aristotélicos que colocam a lógica formal (logos) em seu topo argumentativo. Essa lógica, porém, não se separa de uma possível relação com as paixões (pathos), provocadas pelas defesas que o orador Kelsen (ethos), em sua autoridade e com seus enunciadores, faz de sua própria obra e de si mesmo, quando justifica e defende a teoria da autonomia do Direito ou, ainda, a separação da ciência jurídica dos demais ramos do conhecimento.

Assim, a suposta "ordem autônoma" (MEYER, 2000) do conhecimento, evocada por Kelsen, acaba por fundir-se e manifestar-se no próprio ser (sujeito) que a cria; e a contingência (atributo das paixões) se revela, portanto, como algo que é, ao mesmo tempo, necessário e natural, tendo em

\footnotetext{
${ }^{4}$ Em concordância com Lima (2016), consideramos que "a dimensão patêmica relaciona-se à mobilização das emoções com fins persuasivos, mas também à expressão das emoções" (LIMA, 2016, p. 250, nota 10).
} 
vista o contexto da época em que escreveu, em meio às turbulências das guerras mundiais 5 e às polêmicas suscitadas pelo seu discurso positivista.

\section{O Prefácio como arranjo linguageiro para a narrativa do ser}

De acordo com a pesquisadora Ida Lucia Machado (2014b), em linhas gerais, podemos afirmar que o sintagma narrativa de vida [récit de vie] (BERTAUX, 2005 [1997]) foi empregado para dar corpo a uma teoria discursiva, com viés socioantropológico, na qual o sujeito toma a palavra para falar-de-si, do seu mundo, de suas ideias, e, ao mesmo tempo, para se (re)construir pelo discurso. Desse modo, entendemos que "a narrativa de vida ajuda aquele-quese-narra a melhor se definir face ao outro pelo trabalho que empreende ao elaborar uma imagem de si que opere uma reunião de suas experiências passadas com seu percurso atual” (MACHADO, 2014b, p. 1131).

Em concordância com Machado (2014), acreditamos que as narrativas de vida podem ser estudadas na Análise do Discurso (AD) e, em particular, pelas vias da Semiolinguística, de Patrick Charaudeau, tendo em vista a sua relação com os conceitos da linguística discursiva, e também a sua abertura a outros campos teóricos, "vindos de universos de saber tais como a sociologia, a antropologia, a etnologia, a psicologia social” (MACHADO, 2014b, p. 1131).

Nessa perspectiva, o ato de falar-de-si também pode ser analisado pelas vias das teorias da argumentação, uma vez que estas trazem significativas contribuições sobre as implicações das emoções nos discursos. Esse gesto de exposição do eu face ao outro pode ser revelador para as análises referentes às estratégias de persuasão, dado que as emoções e os efeitos gerados por elas revelam mecanismos de argumentatividade, elementos importantes para a compreensão da retórica que brota desse discurso.

A narrativa de vida, na visão de Machado (2014), pode surgir em certas práticas discursivas "quando menos se espera, e não somente nos relatos a ela consagrados" (MACHADO, 2014b, p. 1132). Desse modo, o Prefácio, como gênero textual que apresenta uma obra, também pode trazer as marcas dos

\footnotetext{
${ }^{5}$ É importante destacar que o contexto em que Kelsen escreveu sua obra Teoria Pura do Direito (1934) encontra-se marcado pelas duas Grandes Guerras Mundiais: a Primeira, de 1914 a 1918, na qual o Império Austro-húngaro participava da Tríplice Aliança, formada em 1882; e a Segunda, de 1939 a 1945, envolvendo a maior parte das nações do mundo, incluindo as grandes potências, que se organizaram em duas alianças militares opostas: os Aliados e o Eixo. Sem dúvida, esse contexto bélico marca as condições de produção do texto de Hans Kelsen e também influencia no modo como o jurista constrói o seu positivismo jurídico.
} 
relatos de si, abrindo as portas das memórias daquele que se narra. Nesse sentido:

$\mathrm{O}$ ato de falar-de-si às vezes se imiscui ao falar-de-seu-trabalho ou, no caso de intelectuais, ao falar teórico. Tal tipo de discurso não contém o objetivo explícito de contar a trajetória de vida de seu enunciador: mas, mesmo assim este a deixa transparecer, por meio das emoções ou de certo tom que é dado, de repente, a esse tipo de discurso (MACHADO, 2014b, p. 1132).

O Prefácio, especialmente aquele que escreveu Hans Kelsen, deixa transparecer a trajetória de vida do jurista austríaco, na condição de filósofo e teórico do Direito, bem como o contexto de produção da sua obra. Além disso, é possível perceber, por meio do referido Prefácio, como se deu a recepção das ideias de Kelsen pelos leitores da época.

Mas, afinal, o que se entende por Prefácio? Seria um texto inaugural que incita expectativas no futuro leitor da obra prefaciada ou seria uma explicação dos modos de produção da obra com sua justificativa de existência? E ainda, seria o Prefácio um arranjo linguageiro que apresenta o fundamento de validade de uma teoria ou uma apologia ao seu criador? Por fim, é possível afirmar que o sujeito prefaciador se revela, trazendo um relato de si, quando escreve um Prefácio? Segundo Charaudeau (1988):

[...] o prefácio responde também a uma expectativa, que está inscrita no contrato comunicacional que o define: ele representa uma caução de verdade [...], e para isso exige que alguém (de renome, na medida do possível) o assine; deve colocar o conteúdo da obra dentro de uma problemática mais ampla; permite ao seu autor estabelecer uma relação entre as ideias expostas na obra e suas próprias ideias; deve, enfim, colocar em evidência os pontos fortes do seu conteúdo (CHARAUDEAU, 1988, p. 5, apud MACHADO, 2014b, p. 1133).

Levando em consideração que o Prefácio exige uma autoridade ou alguém importante que o assine (CHARAUDEAU, 1988), torna-se bastante curioso quando nos deparamos com um texto dessa natureza, cujo prefaciador é o próprio autor da obra em comento. Para nos certificar de que esse texto de Kelsen se trata realmente de um Prefácio, recorremos à obra original, escrita em alemão, e verificamos que o vocábulo na língua original é "vorwort", que se traduz para o português como Prefácio ${ }^{6}$. Também fizemos uma consulta sobre o assunto a alguns pesquisadores ${ }^{7}$ da Faculdade de

\footnotetext{
${ }^{6}$ Cf.: DICIONÁRIO Escolar Alemão Michaelis. Disponível em: http://michaelis.uol.com.br/escolaralemao/busca/alemao-portugues/vorwort. Acesso em: 15 nov. 2017.

7 Entre eles, destacamos o professor pesquisador Dr. Verlaine Freitas, que esclareceu o uso dos prefácios nas obras de Filosofia e, inclusive, mencionou o caso de NIETZSCHE, que escreveu "CINCO PREFÁCIOS para cinco livros não escritos".
} 
Filosofia e Ciências Humanas da UFMG (FAFICH), e descobrimos que a prática de se autoprefaciar ${ }^{8}$ é bastante recorrente na Filosofia, em razão da natureza reflexiva própria desse campo do saber.

Diante desse fato, o contrato comunicacional ${ }^{9}$ (CHARAUDEAU, 1983, p. 50), entre o sujeito comunicante Kelsen, seus enunciadores e seus receptores, foi instaurado numa perspectiva que envolve a junção do ethos e do pathos desse sujeito-que-se-narra. Em outras palavras, nota-se a presença narcisista do "eu" que apresenta e justifica a sua obra. É possível reconhecer a carga valorativa emocional na escolha desse sujeito prefaciador, ao mesmo tempo comunicante e enunciador, que não se desloca para o outro e se centra em si mesmo. Na seção seguinte, analisaremos as implicações das emoções nesse Prefácio proveniente do discurso do filósofo fundador da teoria positiva do Direito.

2. A gênese do pathos aristotélico e o possível diálogo com as origens do positivismo jurídico de Kelsen

Segundo Meyer (2000), o pathos, na perspectiva aristotélica, pode ser sintetizado como "o momento contingente e problemático que busca reencontrar a natureza das coisas, sua finalidade própria, determinada pela essência" (MEYER, 2000, p. XXXIII). Desse modo, o pathos pertence a "um lugar impossível da diferença proposicional sem a qual não haveria identidade de substância” (MEYER, 2000, p. XXXIV). O pathos também pode se tornar paixão, "expressão da natureza humana, da liberdade, comprometido com a ética, portanto com a ação, que transforma a paixão de preferência em virtude" (MEYER, 2000, p. XXXV).

Nessa dimensão patêmica, entendemos que os argumentos de Kelsen, ao defender uma Teoria Pura do Direito, separando-a das outras ciências e atribuindo-lhe uma identidade própria, isolada e única, também estão envoltos na contingência das paixões. Essa analogia com as ideias de Aristóteles, resgatadas por Meyer (2000), se justifica, uma vez que a teoria de Kelsen parece sintetizar esse reencontro obstinado com a própria natureza das coisas, além de uma determinação do objeto do direito que se faz pela

\footnotetext{
${ }^{8}$ Considerando que, normalmente, os prefácios são escritos por um terceiro convocado, sugerimos os termos autoprefaciar / autoprefácio como referência ao gênero textual em análise, que revela as marcas, enunciativas e sociais, do próprio autor da obra prefaciada.

${ }^{9}$ Em linhas gerais, Charaudeau (1983) propõe a noção de contrato comunicacional associada às regras ou normas que regem as interações provenientes de qualquer ato comunicativo.
} 
essência procedente da noção filosófica da norma fundamental. No primeiro parágrafo do Prefácio de 1934, Kelsen faz um relato de si ao afirmar:

Há mais de duas décadas que empreendi desenvolver uma teoria jurídica pura, isto é, purificada de toda a ideologia política e de todos os elementos de ciência natural, uma teoria jurídica consciente da sua especificidade porque consciente da legalidade específica do seu objeto (KELSEN, 1934, p. XI, 2003).

Ao enunciar em tom preambular o "empreendimento" de uma "teoria jurídica pura", o sujeito comunicante Kelsen convoca um sujeito enunciador que assume o papel do cientista do Direito, fundador do positivismo jurídico. Essa voz enunciadora parece explicitar o percurso da construção de sua teoria jurídica, com base em expressões hiperbólicas como: "há mais de duas décadas", "purificada de toda a ideologia" e "de todos os elementos de ciência natural". Essa perspectiva temporal conjugada ao "eu", presente no verbo "empreendi", parece ser uma estratégia de captação de leitores para conferir credibilidade a esse "cientista-jurídico" que interpela os seus sujeitos receptores, idealizados e interpretantes, a respeito da cientificidade e da seriedade da sua proposta. Além disso, há um apelo emocional, no fragmento citado, que recai sobre esse sujeito prefaciador quando expõe a sua pretensão de associar o Direito a uma pureza científica e a uma particularidade do seu objeto.

Portanto, há uma expressão do exagero como argumento retórico desse enunciador que incorpora uma "licença estilística para facilitar a aceitação do argumento" (REBOUL, 2001, p.114). Assim nos diz Reboul (2001), a respeito da argumentatividade e do caráter persuasivo das figuras retóricas: “A figura só é de retórica quando desempenha papel persuasivo” (REBOUL, 2001, p. 113). Entende-se por figura retórica a presença de "qualquer tipo de recurso ou manipulação da linguagem com fins persuasivos, expressivos ou estéticos com o objetivo de ampliar o significado ou a ênfase que o orador quer imprimir em seu discurso" (REBOUL, 2001, p. 113).

Nos dizeres de Kelsen, é possível reconhecer o fim expressivo enfático do seu discurso de justificação que é apresentado, no Prefácio, com mecanismos linguísticos argumentativos presentes nas escolhas lexicais. Assim, o sujeito enunciador, numa empreitada centrada no "eu" que cria a Teoria Pura do Direito, se afasta da noção de que o saber científico, em regra, é construído por meio do compartilhamento de outros saberes e de outras vozes que se fazem presentes nessa construção. Esse enunciador também parece querer nos convencer de que a sua teoria do Direito se afasta de outras 
existentes, uma vez que se encontra "purificada de toda a ideologia política e de todos os elementos de ciência natural” (KELSEN, 1934, p. XI, 2003).

Importante recordar que Kelsen escreveu em um período histórico conturbado e marcado pela ideologia nazista que se propagou na Alemanha do início do século XX. A marca temporal de 1934, presente na publicação da $1^{\text {a }}$ edição da Teoria Pura do Direito, é significativa quando avaliamos o plano externo do discurso e sua relação com a historicidade. Essa data nos remete à Noite das Facas Longas, ocasião em que Adolf Hitler liderou uma facção com o intuito de expurgar políticos contrários ao nazismo, por meio de execuções políticas de natureza extrajudicial. Esse expurgo foi um ato que consolidou o apoio do exército alemão a Hitler e forneceu uma forte base jurídica para o nazismo, tendo em vista que os tribunais alemães demonstraram lealdade ao regime, pois desconsideraram as proibições de execuções extrajudiciais (WHEELER-BENNETT, 2005).

Além disso, Kelsen era judeu, o que nos faz pensar nos dilemas que viveu nessa época para publicar uma obra, em alemão, que anunciava uma doutrina do Direito a partir de uma ruptura com "os elementos de ciência natural” e que, ainda, espelhasse uma "purificação da ideologia política". Segundo Joana Neves (2002):

Os judeus tiveram decretada sua "incapacidade legal permanente", tornando-se alvos de perseguições de toda a ordem. [...] leis radicais foram impostas [...], excluindo os judeus do voto e das atividades comerciais e industriais, confinando-os em guetos ou campos de concentração e expulsando-os do país (NEVES, 2002, p. 444).

Assim, Kelsen convoca outro sujeito enunciador, em seu Prefácio, que assume o papel social do jurista que defende a si próprio das perseguições dos seus opositores da época, dado que a metodologia jurídica que pretende Kelsen busca um afastamento do Direito em relação às ideologias políticas, que, em sua perspectiva, possuem efeitos meramente negativos. Esse enunciador argumenta a respeito da dificuldade dos seus adversários de "fazer justiça” a uma teoria do Direito que contém esse tipo de exigência, ou seja, "a pureza do Direito". Essa afirmação parece abrir um pressuposto interpretativo de que a ciência do Direito, antes da proposta da teoria pura, defendida por Kelsen, encontrava-se contaminada por essa ideologia política de efeitos nefastos que a colocava como posição de destaque por aqueles que a seguiam. É o que parece expressar essa voz prefaciadora no excerto seguinte: 
Em vista dos efeitos políticos - meramente negativos - que importa a postulada desvinculação da política, em vista desta autolimitação da ciência jurídica que muitos consideram como uma renúncia a uma posição de destaque, é compreensível que os opositores se sintam pouco inclinados a fazer justiça a uma teoria que põe tais exigências (KELSEN, 1934, p. XIII, 2003).

No fragmento citado, há duas implicações discursivas que expressam justificativa ou razão e que são introduzidas pela expressão linguística "em vista de": uma que justifica a postulação da teoria jurídica desvinculada da política; e outra, que esclarece a não aceitação dos opositores de Kelsen a respeito da sua "teoria purificada da ideologia política". Essa forma de articulação dos dizeres parece contribuir para o discurso de defesa que o enunciador faz de sua teoria e das ideias que dela se depreendem. Há uma declaração de que os opositores não aceitam a referida teoria, tendo em vista a suposta ameaça de se perder a "posição de destaque" que a ciência jurídica parecia ocupar, antes da limitação pretendida por Kelsen.

Além disso, a escolha dos dizeres "é compreensível”, "se sintam pouco inclinados", "fazer justiça" e "tais exigências" parece compor um jogo de articulações argumentativas, empregadas por Kelsen, como argumento retórico para mostrar a seus censores a superioridade de suas próprias ideias e como elas se afastam da noção do Direito, que se encontrava contaminado por esses efeitos políticos negativos. Trata-se, assim, do fundamento de validade que esse enunciador convoca para reafirmar a necessidade de uma Teoria Pura do Direito.

Ora, na condição de Analistas do Discurso e como sujeitos interpretantes, sabemos que o Direito positivo é fruto de Instâncias legitimadoras que fazem parte dos aparelhos ideológicos de Estado e, por isso, carrega em si as formações discursivas ideológicas na sua própria essência enunciativa. $\mathrm{Na}$ perspectiva de Pêcheux, as ideologias são feitas de práticas sociais e "a luta de classes 'passa por' aquilo que Althusser chamou os aparelhos ideológicos de Estado" (PÊCHEUX, 2014, p. 130). No que se refere ao discurso do Direito, é possível afirmar que as condições de produção desse discurso passam pela noção de que os aparelhos ideológicos de Estado refletem, de forma simultânea e contraditória, "o lugar e as condições ideológicas da transformação das relações de produção" [...] (PÊCHEUX, 2014, p. 130). É por meio da instalação dos aparelhos ideológicos de Estado, ainda que estes não sejam "puros instrumentos da classe dominante" (PÊCHEUX, 2014, p. 130), que se nota a presença da ideologia como aspecto caracterizador da positivação da lei. 
Desse modo, entendemos que há uma grande contradição na suposta "pureza do Direito" convocada por Kelsen, uma vez que o Direito positivo é posto pelo poder soberano do Estado e "nasce do impulso histórico para a legislação" (BOBBIO, 1995, p. 119).

Em outra passagem do Prefácio de 1934, Kelsen declara:

Em todos os países civilizados, em todos os domínios da variada atividade jurídica, tanto nos teóricos como nos práticos, e até da parte de representantes de ciência afins, encontrei adesões animadoras. Formou-se um círculo de pensadores orientados pelo mesmo escopo e a que se chama a minha "Escola", designação que apenas vale no sentido de que, nesta matéria, cada qual procura apreender do outro sem que, por isso, renuncie a seguir o seu próprio caminho (KELSEN, 1934, p. XI, 2003).

Algumas enunciações, presentes nesse fragmento, se destacam e despertam a nossa atenção. Primeiramente, essa ênfase de que em "todos os países civilizados" e "em todos os domínios da variada atividade jurídica", houve adesões às ideias de Kelsen. Novamente, é possível reconhecer a figura retórica da hipérbole e suas marcas de exagero como estratégia persuasiva que parece conduzir os sujeitos receptores à credibilidade das ideias propostas pelo enunciador. Há também, no fragmento supracitado, a expressão de uma supremacia a respeito daquilo que o sujeito enunciador entende como "países civilizados". O enunciado sugere a existência de "outros países" que não aderiram às ideias de Kelsen, e que, por isso, não podem ser considerados civilizados, dado que o "privilégio" da compreensão do positivismo e a consequente adesão de suas ideias se limitam ao que foi proposto como civilização.

Nesse sentido, a exclusividade e o exagero, presentes no plano enunciativo "todos os países civilizados", trazem também as marcas patêmicas, conforme perspectiva de Aristóteles. A junção desses enunciados cria uma proporção de identidade para os sujeitos que possuem capacidade de adesão às ideias de Kelsen, o que os separa dos outros sujeitos que não pertencem ao círculo criado pelo enunciador. Este assume, aqui, o papel de fundador da doutrina jurídica que inaugura uma Escola específica de pensamento, intitulada como "minha Escola". Assim, a paixão conduz ao exclusivo, à rejeição, à negação e aos excessos nos julgamentos, podendo revelar-se também em um momento retórico de resposta às problemáticas (MEYER, 2000). 
O positivismo de Kelsen brota desse ajuste retórico que determina a própria identidade de quem cria o discurso positivo e de quem se alia ao seu pensamento, por meio das "adesões animadoras" desses sujeitos do mundo "civilizado" que formaram o referido "círculo de pensadores orientados pelo mesmo escopo" (KELSEN, 1934, p. XI, 2003). Assim, esse sujeito enunciador determina uma múltipla identidade para si, assumindo os papéis de cientista, filósofo, teórico-fundador do Direito positivo e jurista, bem como para os outros, "tanto nos teóricos como nos práticos, e até da parte de representantes de ciência afins" (KELSEN, 1934, p. XI, 2003).

Segundo Meyer (2000), a argumentação retórica, que tem o propósito de convencer, "insiste na identidade entre o orador e o auditório, mas a argumentação é apenas uma modalidade retórica entre outras, já que se pode muito bem querer reforçar a diferença ou simplesmente sancioná-la" (MEYER, 2000, p. XLII).

Os múltiplos sujeitos da linguagem, convocados por Kelsen, declaram que há um "círculo de pensadores orientados pelo mesmo escopo". Ao declarar a presença dos adeptos à "minha Escola", nota-se o tom narcisista desse sujeito que não se esquiva de trazer a marca da primeira pessoa do singular para seu discurso. Esse sujeito parece se fundir em sua própria teoria ou a teoria parece não se desprender do seu sujeito.

Para Aristóteles, a retórica tem como fim um julgamento e, por isso, o orador deve direcionar a atenção não só para o discurso, "a fim de que ele seja demonstrativo e digno de fé, mas também pôr-se a si próprio e ao juiz em certas disposições"; [...] (ARISTÓTELES, 2000 p. 3). Nessa esteira, Lima (2009) esclarece: "Assim como o pathos, o ethos consiste em um recurso usado para incitar a emoção através do discurso. Essa prova ${ }^{10}$ refere-se, grosso modo, à construção de imagens de si e, ao lado do pathos, é responsável por garantir a adesão do auditório" (LIMA, 2009, p. 58).

Desse modo, para que a persuasão seja produzida nos processos de julgamento, é importante que "o orador se mostre sob certa aparência e faça supor que se acha em determinadas disposições a respeito dos ouvintes e, além disso, que estes se encontrem em semelhantes disposições a seu respeito" (ARISTÓTELES, 2000, p. 3).

\footnotetext{
${ }^{10}$ Segundo Lima (2009), o sentido do termo "prova", empregado aqui na perspectiva aristotélica, refere-se às estratégias usadas pelo orador, em seu discurso, e que são consideradas como "dependentes da arte (retórica)".
} 
Essas marcas discursivas que determinam as "semelhantes disposições", entre orador e auditório, também revelam as suas diferenças. Vejamos o fragmento seguinte:

Também não é pequeno o número daqueles que, sem se confessarem adeptos da Teoria Pura do Direito, em parte sem a mencionar ou até mesmo rejeitando-a aberta e pouco amistosamente, tomam dela resultados essenciais. Para estes, particularmente, vão os meus agradecimentos, pois que eles, melhor que os mais fiéis adeptos, demonstram, mesmo contra a sua vontade, a utilidade da minha doutrina (KELSEN, 1934, p. XI, 2003).

Nessa passagem, a voz prefaciadora parece se investir de estratégias retóricas para expressar, com ironia (MACHADO, 2014a) ${ }^{11}$, a sua gratidão ("meus agradecimentos") àqueles que, mesmo rejeitando a sua teoria, demonstram a sua utilidade, uma vez que "tomam dela resultados essenciais" (KELSEN, 1934, p. XI, 2003). Esse enunciador de Kelsen parece reforçar a imagem da relevância da sua Teoria Pura do Direito e que ela se diferencia das outras que se produziram na doutrina jurídica de sua época. Nota-se, novamente, o apelo emocional em sua escolha lexical, quando evoca enunciações como "meus agradecimentos", "melhor que os mais fiéis adeptos", "minha doutrina", o que, sem dúvida, parece ser uma estratégia retórica que tem por objetivo cristalizar"12 a imagem do sujeito criador da "nova teoria", bem como o valor de suas ideias que se propagam, ainda que haja discordância em relação a elas.

Os efeitos patêmicos se tornam evidentes se considerarmos que, para Aristóteles, as paixões se referem àqueles sentimentos que, ao provocarem alterações nas pessoas, "fazem variar seus julgamentos, e são seguidos de tristeza e prazer, como a cólera, a piedade, o temor e todas as outras paixões análogas, assim como seus contrários" (ARISTÓTELES, 2000, p. 5). Essa perspectiva aristotélica sobre o pathos se nota também na passagem seguinte, que revela os sentimentos dos adversários de Kelsen e as reações provocadas pela Teoria Pura do Direito no meio jurídico:

\footnotetext{
${ }^{11}$ De acordo com Machado (2014a, p. 117): “O sujeito-irônico prefere - por uma razão ou outra enunciar algo por meio de uma não-verdade que o protegerá, sem dúvida, das sanções que um enunciado muito agressivo ou direto poderia provocar. Quando inserida na comunicação, a ironia faz parte de um jogo lúdico, jogo de gato e rato - por vezes cruel - entre os sujeitos da comunicação. A partir desse raciocínio acreditamos poder incluílla no vasto mundo da argumentação".

${ }^{12}$ Nesse sentido, "as paixões cristalizam as relações recíprocas e fixam as imagens da própria natureza do eu no outro" (MEYER, 2000, p. XL).
} 
Esta (referindo-se à “minha doutrina”), além de adesões e imitações, provocou também oposição - oposição feita com uma paixão quase sem exemplo na história da ciência jurídica e que de farma (sic) alguma se pode explicar pelos contrastes de posições que nessa altura vieram à luz. Com efeito, estes baseiamse em parte em más interpretações que, para mais, freqüentemente parecem não ser completamente desprovidas de uma intenção e que, mesmo quando sejam sinceros, a custo podem justificar o profundo azedume dos adversários (KELSEN, 1934, p. XI -XII, 2003).

O sujeito enunciador, nesse fragmento, destaca o "azedume dos adversários" e as oposições que foram feitas à doutrina kelseniana "com uma paixão quase sem exemplo na história da ciência jurídica” (KELSEN, 1934, p. XI -XII, 2003). Em A Retórica das Paixões, Aristóteles comenta sobre as contingências que levam as pessoas aos sentimentos de cólera, inveja e desprezo. Afirma o filósofo grego que o sentimento de cólera quase sempre está associado também ao prazer que o acompanha, "porque as pessoas passam o tempo vingando-se em pensamento; a imagem que então surge causa prazer como a dos sonhos" (ARISTÓTELES, 2000, p. 7). E o desprezo "é a atualização de uma opinião acerca do que não parece digno de consideração" (ARISTÓTELES, 2000, p. 7).

Esse desdém ou desprezo parece ser o sentimento que o sujeito enunciador kelseniano explicita, nesse fragmento, quando afirma que as oposições que foram feitas em relação às suas ideias são provenientes das "más interpretações" dos seus adversários e que dificilmente são justificáveis, uma vez que a sinceridade ("mesmo quando sejam sinceros") é colocada em xeque nesse juízo avaliativo que o enunciador faz de seus oponentes. Aristóteles comenta que "desdenhamos tudo o que julgamos ser desprovido de valor" (ARISTÓTELES, 2000, p. 7).

Assim, como articulação retórica que busca, uma vez mais, captar a adesão de seus interlocutores, Kelsen coloca os seus adversários numa posição quase de nulidade ou invalidade de seus argumentos, especialmente, quando afirma que a refutação deles é “destituída de qualquer conteúdo, é um jogo vazio de conceitos ocos" (KELSEN, 1934, p. XIII, 2003). E, ainda, que os argumentos empregados por eles (ou a ausência desses argumentos) "a custo podem justificar o profundo azedume". Em outras palavras, o enunciador parece nos dizer que não há argumentatividade nas opiniões dos oponentes que possam ser levadas em conta para dar descrédito à sua doutrina. 
Meyer, em A Retórica, afirma que a paixão "é uma resposta àquilo que o próprio locutor adianta como resposta” (MEYER, 2007, p. 38). Dessa forma, o auditório pode responder às questões tratadas pelo locutor de modo a "(1) aderir, (2) recusar essas respostas, (3) completá-las, (4) modificá-las, (5) permanecer silencioso, o que pode ir na direção (6) de aprovação ou (7) de reprovação" (MEYER, 2007, p. 39). Ao levar em consideração as paixões dos seus adversários, Kelsen se coloca na posição de um orador que traz a subjetividade para a cena argumentativa e, com isso, fortalece o seu próprio argumento, também subjetivo, do valor de sua Teoria Pura do Direito.

O discurso patêmico articulado pelos sujeitos da linguagem convocados por Kelsen, sobre suas ideias, seus receptores e sobre si mesmo, leva, portanto, às cristalizações das imagens que se fixaram, ao longo dos tempos, nos imaginários sociodiscursivos (CHARAUDEAU, 2006) dos pensadores e aplicadores do Direito. Importante comentar que, para a ciência jurídica, o nome Kelsen é evocado quase como uma metonímia do que se entende por positivismo jurídico. As ideias kelsenianas se cristalizaram de tal forma nos discursos do Direito que, normalmente, leituras hermenêuticas que escapam a esse posicionamento positivista não são bem vistas ou toleradas no cenário jurídico brasileiro. Ao que parece ser, essa força do positivismo jurídico, criado por Kelsen, vem da própria articulação retórica que o criou e que foi deixada como legado para a ciência do Direito, uma vez que "a retórica tem como fim um julgamento" (ARISTÓTELES, 2000, p. 3).

\section{Considerações Finais}

As paixões possuem uma dimensão que é, ao mesmo tempo, intelectual e epistêmica (MEYER, 2000), pois se materializam como imagens mentais que se cristalizam no discurso e que podem gerar diferentes reações como aprovação, rejeição, reconhecimento ou desprezo. Na perspectiva aristotélica, sabemos que o orador, muitas vezes, movido pela ambição, busca a aprovação do auditório para que seja reconhecida a superioridade daquele que enuncia sobre aqueles que participam da interlocução.

Nessa esteira, o discurso da superioridade evocado por Kelsen, em seu Prefácio, foi construído com as marcas do pathos e do ethos que trouxeram significativos elementos retóricos voltados para a emoção na elaboração e divulgação de suas ideias sobre o positivismo jurídico. Conforme afirmamos 
neste estudo, a doutrina criada por Kelsen tem sido perpetuada, pelos juristas da contemporaneidade, como força ideológica inspirada na lógica formal.

Nessa construção das ideias kelsenianas, destaca-se a força discursiva do Prefácio analisado que, além de revelar os jogos de emoção em seus arranjos linguageiros, traz também os fundamentos de validade e as justificativas de criação do positivismo jurídico, segundo a ótica do sujeito que o criou. Essa explicitação do Direito positivo se funde com as narrativas de vida do sujeito comunicante Kelsen, que, ao evocar múltiplos sujeitos enunciadores, com os seus papéis sociais determinados (jurista, teórico, filósofo e cientista do Direito), traz o foco do seu objeto científico para a imagem que constrói de si, na condição de magistrado de Viena que apresenta uma "nova teoria" para o saber científico de sua época.

O Prefácio, então, escrito e assinado pelo próprio autor da obra em referência, se revela como uma grande metáfora que simboliza o próprio distanciamento que pretendeu Kelsen quando discorreu sobre a "purificação do Direito", uma vez que a autoridade que o assina é o próprio sujeito que o cria, afastando-se, portanto, da figura do outro.

Se pensarmos nesse afastamento do Direito em relação às outras ciências e às ideologias políticas, como pretendia Kelsen, podemos também refletir sobre o que de fato seria, para Kelsen e seus seguidores, prejudicial à ciência jurídica se esta dialogasse com as outras ciências ou com a política. Talvez seja esta a pista para a compreensão do motivo que desencadeou o afastamento da Retórica (século XIX) e a consequente reinvenção dos estudos sobre a argumentação (século $X X$ ), uma vez que a Retórica foi considerada imprópria ao saber positivista (LIMA, 2016, p. 241), conforme afirmamos.

Se considerarmos que a doutrina positivista jurídica afasta o diálogo com as outras ciências, com a ideologia política e com os outros ramos do saber, em razão da suposta "pureza do Direito", pretendida por Kelsen, podemos concluir que a aprovação explícita da Retórica pelos positivistas desencadearia uma rede infinita de interpretações que o próprio positivismo condena. Assim, a doutrina jurídica positiva se ergueu pelos mecanismos da Retórica e, ao mesmo tempo, se encarregou de limitar as implicações retóricas em seus discursos. Isso gera um grande paradoxo para o Direito, uma vez que, na lição de Aristóteles, o objeto do componente retórico se pauta em um gênero discursivo por excelência que é a retórica judiciária. Acreditamos, por fim, que, 
ao menos para a análise do discurso jurídico, se encontra nesse paradoxo o caminho para a reinvenção dos estudos sobre a argumentação.

\section{Referências}

ARISTÓTELES. Retórica das Paixões. Introdução, notas e tradução do grego: Isis Borges B. da Fonseca. São Paulo: Martins Fontes, 2000.

BERTAUX, Daniel. Le récit de vie. 2. ed. Paris: Armand Colin, 2005 [1997].

BOBBIO, Norberto. $O$ positivismo jurídico: lições de filosofia do direito. Tradução: Márcio Pugliesi, Edson Bini, Carlos E. Rodrigues. São Paulo: Ícone, 1995.

CHARAUDEAU, Patrick. Da ideologia aos imaginários sociodiscursivos. In: Discurso Político. Tradução: Fabiana Komesu e Dilson Ferreira da Cruz. São Paulo: Contexto, 2006. p. 184-208.

CHARAUDEAU, Patrick. Langage et discours. Paris: Hachette, 1983.

CHARAUDEAU, Patrick. Préface. In: BOYER, H. L'écrit comme enjeu. Paris: Didier, 1988.

CHARAUDEAU, Patrick. Uma teoria dos sujeitos da linguagem. Tradução: Ida Lucia Machado et al. In: MARI, Hugo et al. (Org.). Análise do discurso: fundamentos e práticas. Belo Horizonte: Núcleo de Análise do Discurso FALE/UFMG, 2001. p. 23-38.

GUSMÃO, Paulo Dourado de. Introdução ao Estudo do Direito. 49. ed. rev. e atual. Rio de Janeiro: Forense, 2018.

FIGUEIREDO, Adriana do Carmo. A retórica e as paixões do prefácio de Hans Kelsen: notas sobre o sujeito, o discurso e a Teoria Pura do Direito. In: IV JORNADAS DA ASSOCIAÇÃO LATINO-AMERICANA DE RETÓRICA - V CONGRESSO BRASILEIRO DE RETÓRICA, 2018, Universidade Federal de Minas Gerais (UFMG). Programação Completa e Resumos das Comunicações. Belo Horizonte: SBR, ALR e UFMG. p. 15.

KELSEN, Hans. Teoria Geral do Direito e do Estado. 3. ed. Tradução: Luis Carlos Borges. São Paulo: Martins Fontes, 2000.

. Teoria Pura do Direito. 6. ed. Tradução: João Baptista Machado. São Paulo: Martins Fontes, 2003.

LIMA, Helcira Maria Rodrigues de. As emoções e sua implicação na construção argumentativa. In: PIRIS, Eduardo Lopes; OLÍMPIO-FERREIRA, Moisés. Discurso e Argumentação em múltiplos enfoques. Coimbra: Grácio Editor, 2016. p. 241-259.

. O olhar do delegado: imagens de si e do outro. Revista da ABRALIN, v. 8, n. 1, p. 57-74, 2009. Disponível em: http://revistas.ufpr.br/abralin/issue/view/2333. Acesso em: 03 dez.2017. 


\section{$\mathrm{El} \square \mathrm{dA}$}

Revista Eletrônica de Estudos Integrados em Discurso e Argumentação, Ilhéus, n. 18, abr.2019.

. STV: Retórica, Argumentação e Emoções. Disciplina ministrada no Programa de Pós-graduação em Estudos Linguísticos (POSLIN). Belo Horizonte: FALE/UFMG, 2017. Notas de aula.

MACHADO, Ida Lucia. A ironia como estratégia comunicativa e argumentativa. Bakhtiniana, São Paulo, n. 9, v. 1, p. 108-128, 2014 a.

. O prefácio visto como uma prática discursiva em que diferentes vidas e obras se entrecruzam. Revista GEL, Campinas, v. 43, n. 3, p. 1129-1139, 2014b.

MEYER, Michel. Prefácio - Aristóteles ou a retórica das paixões. In: ARISTÓTELES. Retórica das Paixões. Tradução: Isis Borges B. da Fonseca. São Paulo: Martins Fontes, 2000. p. XVII-LI.

. A Retórica. Revisão técnica: Lineide Salvador Mosca. São Paulo: Ática, 2007

NEVES, Joana. História geral: a construção de um mundo globalizado. São Paulo: editora Saraiva, 2002.

PÊCHEUX, Michel. Semântica e discurso: uma crítica à afirmação do óbvio. Tradução: Eni Puccinelli Orlandi et al. 5. ed. Campinas: EdUNICAMP, 2014.

PLANTIN, Christian. L’argumentation. Paris: Édtions Seuil, 1996.

REBOUL, Olivier. Introdução à retórica. Tradução: Ivone Castilho Benedetti. São Paulo: Martins Fontes, 2001.

VORWORT. In: DICIONÁRIO Escolar Alemão Michaelis. Disponível em: http://michaelis.uol.com.br/escolar-alemao/busca/alemao-portugues/vorwort. Acesso em: 15 nov. 2017.

WHEELER-BENNETT, John. The Nemesis of Power: The German Army in Politics 19181945. 2. ed. Palgrave Macmillan, 2005.

\section{Forma de citação sugerida}

FIGUEIREDO, Adriana do Carmo. A retórica e as paixões no Prefácio de Hans Kelsen: notas sobre o sujeito, o discurso e a Teoria Pura do Direito. EID\&A - Revista Eletrônica de Estudos Integrados em Discurso e Argumentação, Ilhéus, n. 18, p. 2-19, abr.2019. DOI dx.doi.org/10.17648/eidea-18-2189. 